\title{
Rheological characteristics of extrudates from corn semolina enriched with tapioca flour
}

\author{
Apostol Simitchiev", Mariya Dushkova2*, Nesho Toshkov², Georgi Dobrev³, Anna Koleva4, \\ Ventsislav Nenov ${ }^{1}$ \\ ${ }^{1}$ University of Food Technology, Department of Machines and Apparatus For Food Industry, Plovdiv, Bulgaria, ${ }^{2}$ University of Food Technology, \\ Department of Process Engineering, Plovdiv, Bulgaria, ${ }^{3}$ University of Food Technology, Department of Biochemistry and Molecular Biology, \\ Plovdiv, Bulgaria, ${ }^{4}$ University of Food Technology, Department of Technology of cereal, bread and confectionery products, Plovdiv, Bulgaria
}

\section{A B S TR A C T}

\begin{abstract}
The rheological characteristics of extrudates from corn semolina and mixture of corn semolina and tapioca flour were examined by rotational viscometer "Brookfield" RV-DV II + Pro. A non-linear relationship between the shear stress and the shear rate was established. The model of Ostwald-de Waele was applied and flow and consistency indexes were calculated and used to analyse the rheological behavior of the tested samples. The change of the effective viscosity as a function of the shear rate, depending on the moisture of the mixture, temperature and tapioca content was studied. In this study the addition of tapioca flour to corn semolina increased the viscosity of the extrudates by $60 \%$. The results suggest that tapioca flour influence the rheological properties of food products and can be used as a thickening additive to various kinds of food.
\end{abstract}

Keywords: Corn; Rheology; Tapioca; Viscosity; Extrudates

\section{INTRODUCTION}

Tapioca is a food product which is prepared from the roots of the plant cassava (Manihot esculenta), native to tropical and subtropical areas. It is also known as Cassava, Manihot esculenta, Manioca, Yuca, Balinghoy, Kamoteng kahoy, Mogo, Tapioca - root, kappa (Blagbrough et al., 2010).

Cassava is the third largest source of dietary carbohydrates in the tropics (after rice and sugar cane), also called "bread of the tropics" and it is growing in popularity worldwide. Manioca roots contain carbohydrates in the range of $64-72 \%$, which consist mainly of starch in the form of amylose and amylopectin. Sweet varieties contain about $17 \%$ sucrose and small amounts of fructose and dextrose. The fat content of manioca is only $0.5 \%$. It is rich in minerals (calcium, potassium, iron, zinc, etc.), as well as vitamin C (15 - $45 \mathrm{mg} / 100 \mathrm{~g})$ and, although it is poor in proteins $(1-2 \%)$, its amino acid profile is remarkable in terms of certain essential amino acids, in particular lysine and threonine (Camara et al.,
2001; Charles et al., 2005; Charles et al., 2004). Another important compound with respect to the nutritional value is phytate. It can mostly be found within the shells of nuts, grains and seeds. Phytic acid has a strong binding affinity to many important minerals, such as zinc, calcium and iron, (Dendougui et al., 2004). The studies have shown that cassava contains palmitic, oleic and linoleic acid, and diacid glycerides (Bayoumi et al., 2010). Tapioca represents dried cassava (root) in the form of flour or beads.

In recent years, the demand for gluten-free products is increasing, including tapioca, because the number of people suffering from celiac disease (gluten intolerance) is constantly growing (Stojceska et al., 2010).

Extrusion is a thermo-mechanical treatment which causes the gelatinization of starch, denaturation of proteins, microbial reduction, (des) activation of enzymes and colour changes which are dependent on the extrusion conditions (Martinez et al., 2014). All these changes alter the rheological characteristics of the extrudates (Hagenimana

\footnotetext{
${ }^{*}$ Corresponding author:

Mariya Dushkova, University of Food Technology, Department of Process Engineering, Plovdiv, Bulgaria.

E-mail: maria_douchkova@yahoo.fr
} 
et al., 2006). Mason (2009) reported that the extruded starch and flours may be used as thickening or gelling agents. Extruded sticks of corn semolina are widespread at the markets, but they have a low nutritional value. That is why their mixture with a product which contains many useful properties like tapioca flour may be appropriate. Therefore, the determination of the rheological properties of the resulting extrudates is essential for their proper use. They affect the food quality, texture and consistency. On the other hand, rheological characteristics like shear stress and apparent viscosity can affect important economic indicators during extrusion such as mass flow rate and specific mechanical energy. The interesting properties of tapioca opened the door for our interest in researches related to this product. The purpose of this work is to study the rheological properties of extrudates from corn semolina enriched with tapioca flour.

\section{MATERIALS AND METHODS}

\section{Materials}

The investigation was carried out with corn semolina with a mean particle diameter $\mathrm{d}_{\mathrm{m}}=1.138 \mathrm{~mm}$. Tapioca flour is produced in Thailand and was purchased commercially. 5 and $10 \%$ tapioca flour was added to the corn semolina, then the mixture was stirred by a tumbler mixer MLW 53035 at a speed $\mathrm{n}=50 \mathrm{~min}^{-1}$. Water was added to the samples in order to reach the predetermined moisture. The content of the samples is presented in Table 1.

\section{Composition of the samples}

The starch content (ISO 10520: 1997) and total sugars in tapioca flour and corn semolina were investigated (Dimitrova et al., 2015). The amylose and amylopectin content (Hoover and Ratnayake, 2001) were determined. The total protein (EN ISO 20483: 2006) and total fat (ISO EN 659: 2009) content were analyzed. The ash was determined by the method ICC - Standard N104/1.

\section{Experimental plan}

Multilevel factorial design was used to describe the consistency index and flow index of corn extrudates enriched with tapioca. The independent variables and their levels of variation are presented in Table 2.

\section{Extrusion processing}

The samples were extruded on a laboratory single screw extruder "Brabender" $20 \mathrm{DN}$ (L: D = 20:1) in the following operating regimes:

- Temperatures in all three zones of the extruder, $\mathrm{t}_{1}=120^{\circ} \mathrm{C}, \mathrm{t}_{1}=130^{\circ} \mathrm{C}, \mathrm{t}_{1}=140^{\circ} \mathrm{C}$;

- Diameter of the nozzle $\mathrm{d}=4 \mathrm{~mm}$;

- Compression degree of the screw $K=3: 1$;

- Rotational frequency of the feeding screw $n_{1}=10 \mathrm{~min}^{-1}$;
Table 1: Content of investigated corn semolina samples

\begin{tabular}{lcc}
\hline Sample & Moisture, W, \% & Content of tapioca, T, \% \\
\hline Sample 1 & 13 & 0 \\
Sample 2 & 13 & 5 \\
Sample 3 & 13 & 10 \\
Sample 4 & 17 & 0 \\
Sample 5 & 17 & 5 \\
Sample 6 & 17 & 10 \\
\hline
\end{tabular}

Table 2: Experimental plan

\begin{tabular}{lccc} 
Independent & \multicolumn{3}{c}{ Levels of variation } \\
\cline { 2 - 4 } variables & Low level & Center level & High level \\
\hline Moisture content, W, \% & 13 & - & 17 \\
Tapioca content, T, \% & 0 & 5 & 10 \\
\hline
\end{tabular}

- Rotational frequency of the operating screw $\mathrm{n}_{2}=$ $100 \mathrm{~min}^{-1}$.

\section{Structural and mechanical properties}

After extrusion, the different samples of extrudates were stored for 48 hours in a desiccator and then ground in a laboratory mill. The resulting flour was sifted through laboratory sieve with an orifice of $1 \mathrm{~mm}$. Then $3,5 \mathrm{~g}$ of the sample were weighed $( \pm 0,1 \mathrm{~g})$ and mixed with $25 \mathrm{~g}$ of distilled water ( \pm 0,1 g) (Martinez et al., 2014). The mixture was homogenised for 10 minutes by a homogenizer Warzawa MPW-324 at a speed $\mathrm{n}_{\mathrm{h}}=500 \mathrm{~min}^{-1}$.

The rheological behaviour of the products was studied on a rotary viscometer "Brookfield" RV DV-II + Pro, equipped with an adapter for small samples, comprising a metal cylinder measuring with a water jacket SC4-13R and a cylindrical spindle with conical head SC4-27. The spindle SC4-27 had a length of the tube $33.02 \mathrm{~mm}$ and diameter $11.76 \mathrm{~mm}$ and a total length of working part $39.29 \mathrm{~mm}$. The measuring cylinder had an internal diameter of $19.05 \mathrm{~mm}$ and a length of $64.77 \mathrm{~mm}$. The water jacket of the adapter for small samples was connected by flexible connections with ultra thermostat "Zemail Horyzont", equipped with a contact thermometer with a range from 0 to $100{ }^{\circ} \mathrm{C} \pm$ 0.01 and second control thermometer with the same scope.

The measuring cylinder was filled with a sample of $10.4 \mathrm{ml}$ by pipette and then heated at three different temperatures for a period of 10 minutes. The sample temperature was monitored by a temperature probe with a range from 0 to $\pm 0.1{ }^{\circ} \mathrm{C}$, connected to the viscometer. After reaching the required temperature, on the neck of the cylinder was placed an insulating cap, and then begun the preliminary experiments in order to specify the range of speed gradients for the measurements.

An experiment was designed, during which the samples were heated at temperatures $\mathrm{t}_{1}=30^{\circ} \mathrm{C}, \mathrm{t}_{2}=35^{\circ} \mathrm{C}, \mathrm{t}_{3}=40^{\circ} \mathrm{C}$, then the shear stress was recorded at eight shear rates - 44.2; 
47.6; 51; 54.4; 57.8; 61.2; 64.6; $68 \mathrm{~s}^{-1}$ (rotational frequency of the spindle $\left.130 ; 140 ; 150 ; 160 ; 170 ; 180 ; 190 ; 200 \mathrm{~min}^{-1}\right)$. Each experiment continued 8 minutes - the spindle rotated at each of rotational frequencies for the period of $1 \mathrm{~min}$. The resulting data were used for constructing graphical dependencies between the shear stress and the shear rate which were used to define the rheological properties of the product.

\section{Statistical treatment of data}

Statistical data processing was carried out by specialised software Statgraphics Centurion XVI Trial Version. Three repetitions were made for each sample.

\section{RESULTS AND DISCUSSIONS}

The experiments show that all tested suspensions exhibit non-Newtonian behaviour, since the relationship between the shear rate and the shear stress is non-linear (Rheological curves of flour heated at $\mathrm{t}=35^{\circ} \mathrm{C}$ are presented in Fig. 1). As can be seen, the shear stress $(\mathrm{G}, \mathrm{Pa})$ is increasing with the shear rate $\left(\mathrm{D}, \mathrm{s}^{-1}\right)$. This means that during the extrusion process, the increase in the speed of operating screw has

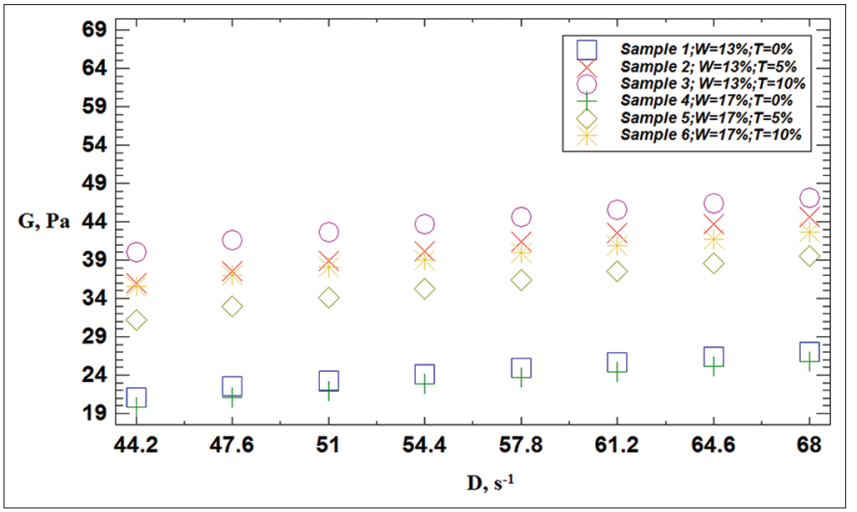

Fig 1. Rheological curves for all samples at temperature $t=35^{\circ} \mathrm{C}$; $\mathrm{G}$ - shear stress, $\mathrm{Pa}$; D - shear rate, $\mathrm{s}^{-1}$. been accompanied by a higher tangential stresses. This, in turn, would lead to an increase in torque during operation, followed by a high energy consumption.

The average values of the results from the experiments are approximated by rheological models of Bingham, Herschel-Bulkley, Ostwald-de Waele and Casson.

The strongest correlation $\left(\mathrm{R}_{2}>98.5 \%\right)$ between the shear stress and the shear rate is achieved when the model of Ostwald-de Waele is applied (Equation 1).

$\mathrm{G}=\mathrm{k} \cdot \mathrm{D}^{\mathrm{n}}$

$\mathrm{G}$ - shear stress, Pa; $\mathrm{k}$ - consistency index, Pa.s ${ }^{\mathrm{n}}, \mathrm{n}-$ flow index.

Equations describing the dependence of the shear stress from the shear rate at different temperatures of heating were obtained for all samples. The coefficients of the equation for each sample are presented in Table 3.

It is common known that the flow index under the power law of Ostwald-de Waele is a measure of deviation from Newtonian behaviour of the products. If the product is Newtonian $\mathrm{n}=1$, if it is pseudoplastic $\mathrm{n}<1$, and dilatant $\mathrm{n}>1$. As the value of $\mathrm{n}$ is close to 1 , as the product has more Newtonian behaviour (i.e. viscosity does not depend on the shear rate). The consistency index is an indicator of the apparent viscosity of the products at shear rate $\mathrm{D}=1 \mathrm{~s}^{-1}$.

Table 3 show that all values of the flow index are less than one ( $\mathrm{n}=0.34-0.63$ ). This indicates that the tested products have pseudoplastic character and distinguish with an inversely proportional relation between the apparent viscosity and the shear rate.

In all examined cases, the flow index increases with the rise in the temperature. This trend can be attributed to an

Table 3: Values of coefficients in Ostwald-De Waele equation for all samples

\begin{tabular}{|c|c|c|c|c|c|c|}
\hline \multicolumn{7}{|c|}{$\mathrm{D}=44.2-68 \mathrm{~s}^{-1}$} \\
\hline $\mathrm{t},{ }^{\circ} \mathrm{C}$ & \multicolumn{2}{|c|}{$t=30^{\circ} \mathrm{C}$} & \multicolumn{2}{|c|}{$\mathrm{t}=35^{\circ} \mathrm{C}$} & \multicolumn{2}{|c|}{$t=40^{\circ} \mathrm{C}$} \\
\hline Index & k, Pa.s ${ }^{n}$ & $\mathbf{n}$ & k, Pa.s ${ }^{n}$ & $\mathrm{n}$ & k, Pa.s ${ }^{n}$ & $\mathbf{n}$ \\
\hline \multicolumn{7}{|l|}{ Sample 1} \\
\hline$W=13 \% ; T=0 \%$ & $5.47 \pm 0.012$ & $0.43 \pm 0.007$ & $2.63 \pm 0.015$ & $0.55 \pm 0.006$ & $1.91 \pm 0.009$ & $0.58 \pm 0.012$ \\
\hline \multicolumn{7}{|l|}{ Sample 2} \\
\hline$W=13 \% ; T=5 \%$ & $10.67 \pm 0.009$ & $0.37 \pm 0.009$ & $5.62 \pm 0.023$ & $0.49 \pm 0.008$ & $3.94 \pm 0.021$ & $0.51 \pm 0.011$ \\
\hline \multicolumn{7}{|l|}{ Sample 3} \\
\hline$W=13 \% ; T=10 \%$ & $13.03 \pm 0.001$ & $0.34 \pm 0.010$ & $9.85 \pm 0.021$ & $0.37 \pm 0.005$ & $4.76 \pm 0.02$ & $0.48 \pm 0.008$ \\
\hline \multicolumn{7}{|l|}{ Sample 4} \\
\hline$W=17 \% ; T=0 \%$ & $3.57 \pm 0.015$ & $0.51 \pm 0.006$ & $2.12 \pm 0.017$ & $0.59 \pm 0.009$ & $1.41 \pm 0.014$ & $0.63 \pm 0.005$ \\
\hline \multicolumn{7}{|l|}{ Sample 5} \\
\hline$W=17 \% ; T=5 \%$ & $7.02 \pm 0.021$ & $0.46 \pm 0.009$ & $4.03 \pm 0.015$ & $0.54 \pm 0.012$ & $2.39 \pm 0.018$ & $0.60 \pm 0.008$ \\
\hline \multicolumn{7}{|l|}{ Sample 6} \\
\hline$W=17 \% ; T=10 \%$ & $11.24 \pm 0.018$ & $0.36 \pm 0.01$ & $7.52 \pm 0.02$ & $0.41 \pm 0.011$ & $3.55 \pm 0.017$ & $0.52 \pm 0.011$ \\
\hline
\end{tabular}


easier degradation of the solids in the liquid medium at a temperature rise. This leads to a more pronounced flow of the products as a result of the rapid destruction of the molecular bonds in the dispersed system. However, the flow index approaches closer to 1 , while the consistency index reduces, as it is shown in Table 3.

The increase in the amount of tapioca in the individual samples leads to an increase of totals sugars and starch content in the flours, as well as a decrease in the total protein, total fats and ash content (Table 4). The large amounts of sugars and starch, in the form of amylose and amylopectin, in the composition of the flours, increase the gelatinization of the product during the high temperature extrusion process. Gelatinization induces many changes of the starch granules such as swelling, exudation of amylose and amylopectin and increased viscosity (Babic et al. 2006). This causes thickening of the final product and increasing viscosity.

Increasing the amount of tapioca, added to the corn semolina leads to an increase in the consistency index and a decrease in the flow index. Zhang et al. (2013) also reported the same trend. Wang et al. (2009) found that in the studies with corn starch the addition of sugars leads to an increase in the consistency index. Similar explanation is logical to look in our study due to the greater amount of sugars and starch in the composition of tapioca. The addition of tapioca to corn semolina leads to a reduction of the flow index with 10 to $30 \%$ for all samples. The moisture of the flours during extrusion also has an effect on their rheological parameters. In the samples containing tapioca, the higher moisture of the mixture gives a reflection on the flow index, which increases in the investigated interval between 7 and $17 \%$, while the consistency index decreases with 17 to $35 \%$. Here the trend is clear - the flours extruded at higher moisture have lower consistency and they are more flowable than those with lower moisture.

The change of the apparent viscosity $(\mu$, Pa.s) of all samples calculated by equation 2 , depending on the shear rate is similar for all investigated samples. Typical curves for all samples are shown in Fig. 2.

$\mu=\mathrm{k} \cdot \mathrm{D}^{(\mathrm{n}-1)}$

The obtained dependences confirm the pseudoplastic behaviour of the investigated flours since the viscosity decreases with the increase in the shear rate. Abdul-Rasaq et al. (2013) and Chantaro et al. (2013) observed the same dependence during the measuring of the viscosity of tapioca flour. The mixing of corn semolina with $5 \%$ tapioca leads to a rapid increase in the apparent viscosity, which varies in the range of 40 to $60 \%$ in different samples. Agudelo et al. (2014) and Hover (2001) reported that the high amylose content in food products leads to a degradation of starch and higher viscosity. In our investigation, the presence of significant amount of starch, under the form of amylose and amylopectin, as the presence of significant amount of sugars in tapioca flour, leads to a thickening of the mixture and an increase in the viscosity. The addition to the samples of complementary amount of tapioca flour increases the apparent viscosity with up to $10 \%$.

The presence of fat, protein and ash in the samples with a greater amount of tapioca does not lead to a reduction

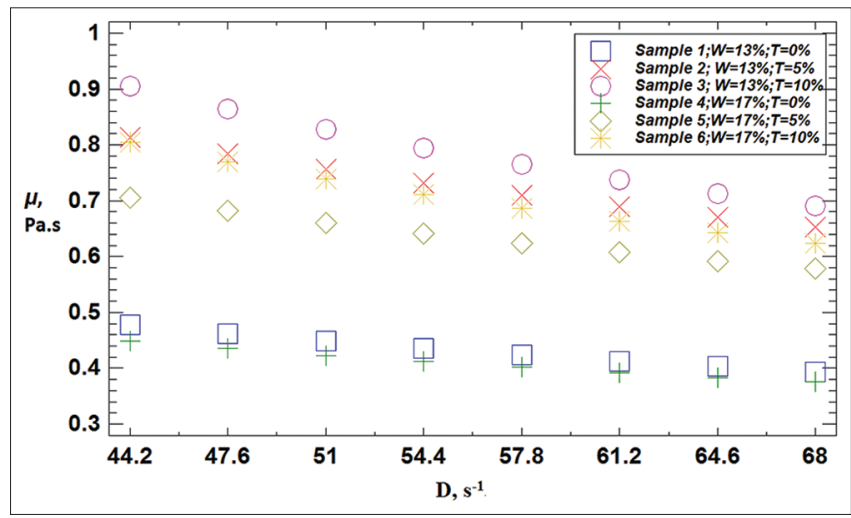

Fig 2. Apparent viscosity changes at different shear rates for all samples at temperature $\mathrm{t}=30^{\circ} \mathrm{C} ; \mu$ - apparent viscosity, Pa.s; D - shear rate, $\mathrm{s}^{-1}$.

Table 4: Composition of the samples

\begin{tabular}{|c|c|c|c|c|c|c|c|}
\hline Sample & Total sugars & Starch & Amylose & Amylopectin & Total protein & Total fats & Ash \\
\hline $\begin{array}{l}\text { Sample } 1 \\
\text { W=13\%; } T=0 \%\end{array}$ & 79,2 & 79,2 & 29,2 & 70,8 & 6,9 & 13,5 & 0,68 \\
\hline $\begin{array}{l}\text { Sample } 2 \\
\qquad W=13 \% ; T=5 \%\end{array}$ & 79,7 & 79,7 & 32,3 & 67,7 & 6,5 & 13,3 & 0,67 \\
\hline $\begin{array}{l}\text { Sample } 3 \\
\qquad W=13 \% ; T=10 \%\end{array}$ & 80,4 & 80,4 & 36,9 & 63,1 & 6,3 & 12,9 & 0,65 \\
\hline $\begin{array}{l}\text { Sample } 4 \\
\qquad W=17 \% ; T=0 \%\end{array}$ & 75,6 & 75,6 & 27,8 & 72,2 & 6,6 & 12,9 & 0,65 \\
\hline $\begin{array}{l}\text { Sample } 5 \\
\qquad W=17 \% ; T=5 \%\end{array}$ & 76,0 & 76,0 & 30,8 & 69,2 & 6,2 & 12,7 & 0,64 \\
\hline $\begin{array}{l}\text { Sample } 6 \\
\qquad W=17 \% ; T=10 \%\end{array}$ & 76,7 & 76,7 & 35,2 & 64,8 & 6,0 & 12,3 & 0,62 \\
\hline
\end{tabular}


in the viscosity (Table 4). This can be explained by the high temperatures during extrusion processing of the flour, which lead to the breakdown of fat and protein denaturation. On the other hand, the increase of the ash content is indicative of a greater amount of dry matter in the sample, respectively. In our case, though, the larger amounts of ash in the samples with pure corn semolina lead to a decrease of the shear stress and the apparent viscosity, as seen in Figs. 1 and 2.

The higher moisture content of the mixtures leads to a reduction of the shear stresses. Explanation, in this case, can be searched in the greater residual moisture content after extrusion, contained in samples 4, 5 and 6. The material treated with high moisture has greater plasticity (Penov, 2000). During the expiring of the product from the extruder nozzle and its primary expansion, a part of the moisture evaporates. The separated moisture, however, is not sufficient to allow the formed skeleton to be fixed (stable), resulting in the formation of shrinkage of its volume, closing of some of the pores formed and the encapsulation of the remainder of the product moisture. This explains the fact that higher moistures in samples 4, 5 and 6 differ by approximately $8 \%$ lower apparent viscosity.

\section{CONCLUSIONS}

The investigated pure corn flours and mixtures of corn semolina and tapioca flour exhibit non-Newtonian behaviour. The relationship between the shear rate and the shear stress is approximated to the power law of Ostwald de-Waele. The mixtures manifest pseudoplastic character and distinguish with an inversely proportional relation between the apparent viscosity and the shear rate. It is established a reduction in the flow index and an increase in the consistency index of the food products when tapioca flour is added. The greater residual moisture content of the samples after extrusion leads to a reduction of the shear stresses. The experiments confirm the effects of tapioca flour as a thickening additive to various kinds of food. As a result of the high starch content, including amylose and amylopectin, and the presence of large amounts of sugars, the tapioca flour is able, even at low concentrations, to increase the apparent viscosity of the corn semolina up to $60 \%$. The obtained results can be used for further research, related to the filling and forming of food products which contain tapioca.

\section{Authors contribution}

A. Simitchiev is responsible for extrusion treatment and rheology analysis and also wrote and revised the manuscript with co-author M. Dushkova. M. Dushkova was the project manager and was involved in the extrusion and rheology treatment and analysis. N. Toshkov was involved in the extrusion process and analysis. A. Koleva collaborated in the mixing of the flours and was involved in the extrusion process and the sample composition analysis. G. Dobrev is responsible for the analysis of starch and sugar content of tapioca and corn semolina and the sample composition analysis. V. Nenov was involved in the rheology analysis.

\section{REFERENCES}

EN ISO 20483: 2006. Cereals and pulses - Determination of the nitrogen content and calculation of the crude protein content.

ICC - Standard N104/1 Determination of Ash in Cereals and Cereals.

ISO 10520: 1997. Native starch - Determination of starch content.

ISO EN 659: 2009. Oilseeds -- Determination of oil content (Reference method).

Abdul-Rasaq, A. A. and L. O. Sanni. 2013. Effect of solid content and temperature on viscosity of tapioca meal. Journal of food science and technology, 50 (3), 573-578.

Agudelo, A., P. Varela, T. Sanz, and S. M. Fiszman. 2014. Native tapioca starch as a potential thickener for fruit fillings. Evaluation of mixed models containing low-methoxyl pectin. Food Hydrocolloids, 35, 297-304.

Babic, J., D. Subaric, D. Ackar, V. Pilizota, M. Kopjar and N. Nedic Tiban. 2006. Effects of pectin and carrageenan on thermophysical and rheological properties of tapioca starch. Czech Journal of Food Sciences, 24 (6), 275-282.

Bayoumi, S. A. L., M. G. Rowan, J. R. Beeching and I. S. Blagbrough. 2010. Constituents and secondary metabolite natural products in fresh and deteriorated cassava roots. Phytochemistry 71 , 598-604.

Blagbrough, I. S., S. Bayoumi, M. Rowan and J. Beeching. 2010. Cassava: An appraisal of its phytochemistry and its biotechnological prospects. Phytochemistry, 71, 1940-1951.

Camara, F. S. and M. S. Madruga. 2001. Cyanic acid, phytic acid, total tannin and aflatoxin contents of a Brazilian (Natal) multimistura preparation. Brazilian Journal of Nutrition, 14, 33-36.

Chantaro, P., R. Pongsawatmanit and K. Nishihari. 2013. Effect of heating - cooling on rheological properties of tapioca starch paste with and without xanthan gum. Food hydrocolloids, 31, 182-194.

Charles, A. L., Y. H. Chang, W. C. Ko, K. Sriroth and T. C. Huang. 2004. Some physical and chemical properties of starch isolates of cassava genotypes. Starch/Starke, 56, 413-418.

Charles, A., K. Sriroth and T. Huang. 2005. Proximate composition, mineral contents, hydrogen cyanide and phytic acid of 5 cassava genotypes. Food chemistry 92, 615-620.

Dendougui, F. and G. Schwedt. 2004. In vitro analysis of binding capacities of calcium to phytic acid in different food samples. European Food Research and Technology, 219 (4), 409-415.

Dimitrova, M., N. Petkova, P. Denev and I. Alexieva. 2015. Carbohydrate composition and antioxidant activity of certain morus species. International journal of pharmacognosy and phytochemical research, 7(3), 621-627.

Hagenimana, A., X. Ding and T. Fang. 2006. Evaluation of rice flour modified by extrusion cooking. Journal of Cereal Science, 43 , 38-46.

Hoover, R. 2001. Composition molecular structure, and physicochemical properties of tuber and root starches: a review. 
Carbohydrate polymers, 45, 253-267.

Hoover, R. and W. Ratnayake. 2001. Determination of total amylose content of starch. Current protocols in food analytical chemistry, Wiley, New York. Section E, Unit 2-3.

Martinez, M., C. Rosell and M. Gomez. 2014. Modification of wheat flour functionality and digestibility through different extrusion conditions. Journal of Food Engineering, 143, 74-79.

Mason, W. R. 2009. Starch use in foods. In: BeMiller, J., Whistler, R. (Eds.), Starch Chemistry and Technology, Academic Press, New York, USA, 745-795.

Penov, N. 2000. Investigating extrusion of spinach flour and wheat semolina mixture for the production of instant foods. University of food technologies, Plovdiv. Thesis.

Stojceska, V., P. Ainsworth, A. Plunkett and S. Ibanoglu. 2010. The advantage of using extrusion processing for increasing dietary fiber level in gluten-free products. Food chemistry, 121, 156-164.

Wang, B., L. Wang, D. Li, N. Ozkan, S. Li and Z. Mao. 2009. Rheological properties of waxy maize starch and xanthan gum mixtures in the presence of sucrose. Carbohydrate Polymers 77 (3), 472-481.

Zhang X., Q. Tong, W. Zhu and F. Ren. 2013. Pasting, rheological properties and gelatinization kinetics of tapioca starch with sucrose and glucose. Journal of food engineering, 114, 255-261. 